DOI 10.20396/temáticas.v11i21/22.13527

\title{
ALGUNS COMENTÁRIOS SOBRE A TEMÁTICA RACIAL NAS OBRAS DE ROGER BASTIDE ${ }^{1}$
}

\author{
Priscila Nucci ${ }^{2}$
}

RESUMO: Roger Bastide é um dos autores relacionados à criação de um campo de estudos sobre o preconceito racial no Brasil. Entretanto, deve-se definir quais as estratégias intelectuais escolhidas pelo autor, ou mesmo os antagonismos internos de seus textos no tratamento de temas como o "preconceito de cor" e a "democracia racial". Neste momento analiso a temática racial através de alguns de seus textos.

UNITERMOS: Roger Bastide; pensamento social brasileiro; história intelectual; relações raciais; preconceito de cor; racismo; candomblé.

\section{INTRODUÇÃO}

A temática da raça aparece em vários momentos da obra de Roger Bastide, mas aparentemente tem uma presença maior em Relações Raciais entre Negros e Brancos em São Paulo (1955). Entretanto, ao se analisar outras obras suas com temáticas como a religião, arte e literatura, o tema reaparece. Des-

\footnotetext{
$1 \mathrm{O}$ presente trabalho foi realizado com o apoio financeiro da Fundação de Amparo à Pesquisa do Estado de São Paulo - FAPESP (a partir de nov/02) e do Conselho Nacional de Desenvolvimento Científico e Tecnológico - CNPq (abr/02 - out/02) e faz parte do desenvolvimento do projeto de doutorado "A elaboração dos saberes sobre o racismo no Brasil e as imagens recriadas dos afro-brasileiros: textos de Roger Bastide sobre religião e anti-racismo”. Esta é uma versão modificada do trabalho de mesmo título apresentado no XI Congresso Brasileiro de Sociologia do SBS, em setembro de 2003.

2 Doutoranda em Ciências Sociais -IFCH/UNICAMP na Área de Pensamento e Desenvolvimento Social.
} 
de o seu primeiro texto escrito no Brasil, Imagens do Nordeste Místico em Branco e Preto (1945), Bastide persegue uma série de temas obsessivos, entre eles a presença africana e negra no país (Peixoto, 2000, p.20).

Ele produz um tipo de texto sobre a situação do negro em centros mais modernizados, como São Paulo e Rio de Janeiro, nos quais as formas da religiosidade de origem africana operariam um sincretismo muito profundo com o catolicismo e o espiritismo, e nos quais surgiria a percepção do preconceito de cor, seja através das relações pessoais como das relações de trabalho. Mas também há outro tipo de análise quando Bastide verifica a situação do negro em locais como a Bahia, nos quais não existiriam nem a industrialização, a modernização ou o desenvolvimento de um capitalismo mais radical nos moldes de São Paulo. Esta é uma primeira dicotomia, na qual aparecerão dois tipos de "relações raciais" dependentes da situação social dos negros. Mas além disto, surgem trechos em Bastide como, por exemplo, em Brasil Terra de Contrastes (1959 [1957]), onde termos como branqueamento e mestiçagem parecem indicar certa oscilação dentro de seu pensamento sobre as "relações raciais" entre brancos e negros.

Estes antagonismos na sua obra, pouco explorados pela literatura existente, podem nos indicar várias possibilidades de análises do autor sobre a "situação racial" na época. Bastide persegue certos temas durante a sua vida, o que implicitamente significa que suas análises podem oscilar, ao invés de ter uma coerência do começo ao fim. Estas oscilações indicam interlocuções com o pensamento social brasileiro e com a sociedade do momento.

\section{O CANDOMBlÉ E OS AFRO-BRASILEIROS}

O primeiro livro de Bastide no Brasil, Imagens do Nordeste Místico em Branco e Preto (1945) reproduz, entre outras coisas, impressões de viagens que o autor realizou para Pernambuco e Bahia. O candomblé e algumas cerimônias são presenciados na Bahia e ele os descreve e analisa como ritos socialmente controlados e, não como era corrente na época, como expres- 
são de psicopatologia. Embora o argumento presente em $O$ Candomblé da Babia (1978 [1958]) e em As Religiões Africanas no Brasil (1971 [1960]) seja bem mais complexo e desenvolvido, análises feitas na primeira viagem, reaparecem e indicam a permanência de certas impressões e posicionamentos quanto aos cultos dos afro-brasileiros na obra de Bastide.

A temática racial se delineava neste e em outros textos, principalmente através da positivação do que era considerado por outros autores como cultural, psicológica e, de forma implícita ou não, racialmente inferior.

A cidade de Salvador que Bastide constrói em seus textos tem uma pulsação diferente, pela presença do candomblé visto pelos olhos estrangeiros: é mística, possui uma religião com metafísica, um povo negro o qual utiliza-se da religião para lutar contra as expropriações da escravidão e dos preconceitos. Mas também é a cidade na qual as definições raciais explodem, seja através da quebra de hierarquias sociais, de cor, ou mesmo através da percepção da miscigenação cultural e racial. Ao pensar nos meandros deste grupo, formado pelos negros do candomblé na Bahia, Bastide percebeu uma série de possibilidades de relações entre brancos e negros, que não existiriam em nenhum outro local do mundo, e mesmo no resto do Brasil, e que dispensariam movimentos organizados contra o preconceito:

“...por que as seitas religiosas africanas que chegaram a lutar contra o regime servil não estão mais hoje em combate contra o que pode trazer reminiscências da situação passada para a presente: preconceito de cor, discriminação racial, concentração da massa de negros nos estratos inferiores da sociedade? Por que essa luta passou dos domínios dos grupos religiosos aos dos grupos de defesa puramente política como a Frente Negra, a Federação das Associações de Brasileiros de Cor e outros? É fácil dar uma resposta a essa questão. De início o regime democrático do país permite às reivindicações de raça como classe exprimirem-se legalmente pelos canais abertos pela Constituição... De outro lado, esses movimentos de protesto racial produzem-se apenas onde os preconceitos e os atos de discriminação estão em seu auge, não podem existir 
onde a democracia racial funciona harmoniosamente, como é o caso da Bahia. Várias tentativas foram aí feitas para reunir os negros e os mulatos escuros nas associações raciais políticas; todos os esforços fracassaram... Como poderia o negro, de fato, protestar contra os brancos quando vê estes se ajoelharem humildemente diante de sua ialorixá para pedir-lhe a bênção, cercar do maior respeito seus últimos babalaôs... A religião africana destrói qualquer outra hierarquia que não se fundamenta na maior ou menor familiaridade com o sagrado, e nos candomblés a situação é radicalmente oposta à do país 'profano': é o homem escuro que domina o homem claro". (Bastide, 1971, pp. 324-325). ${ }^{3}$

Esta mediação efetuada pelo candomblé indica a possibilidade de outro tipo de relação humana, e da não inferioridade imanente do negro brasileiro. As relações de poder se invertem e se modificam qualitativamente. Algo que não foi descrito em detalhe pelos outros africanistas brasileiros agora aparece em Bastide: os próprios pesquisadores deveriam entrar nesta estrutura nova, mas como iniciados, na parte mais baixa da hierarquia. Muitos antropólogos tornaram-se ogãs dos candomblés, o que indica uma iniciação neste mundo. Bastide participou de certos rituais e se iniciou neste universo através dos contatos com a religião e as mães-de-santo, mas ao contrário de seus pares, pretendia uma compreensão mais profunda do outro, através de sua inserção na religião afro-brasileira. (Bastide, 1971, pp. 17-18; Bastide, 1973, pp. X-XI).

Entretanto, o candomblé seria uma religião na qual os "contatos raciais" também poderiam ser negativos para os negros e para as imagens sobre essa religião:

“... Mas a religião do africano é uma religião de controle e não de licença... Se o candomblé, num momento dado, abriu caminho a gestos indecentes, foi por culpa do contato entre as raças, por culpa da entrada dos brancos que vinham procurar perto das filhas-de-santo uma febre de sentidos... A polícia, regulamentando os candomblés, prestou-lhes o serviço de fa-

3 A ortografia original dos textos foi atualizada.

Temáticas, Campinas, 11(21/22):101-126, jan./dez. 2003 
zê-los voltar ao seu puritanismo e à sua antiga pureza: as mulheres são separadas dos homens, é proibido fumar e beber aguardente; a assistência se mantém silenciosa, piedosa, recolhida". (Bastide, 1973, pp. 282-283).

Idéias conservadoras surgem em momentos como este, no qual uma certa imagem de culto prevalece sobre outra. Pureza e puritanismo contra certo predomínio de brancos que somente buscariam a "febre de sentidos" no candomblé, contaminando-o. O controle da polícia visto como regulador da pureza do candomblé é uma constatação bastante estranha. As ações policiais descritas pelos relatos jornalísticos reproduzidos por Arthur Ramos dão a nítida impressão de visar destruir os candomblés. (Ramos, 1988, pp. 106-110). Bastide parece dar-lhes outra função neste trecho, apesar de sua potencialidade destruidora. Neste sentido, ele vê na ação da polícia a regulamentação, a exclusão de elementos estranhos aos rituais, supostamente introduzidos pelos brancos.

A questão da fidelidade dos cultos à África reaparece em Bastide, quando ele infere que os fenômenos patológicos existiriam nos candomblés, mas somente nos cultos nos quais se abandonou a "maior fidelidade à África, à medida que elementos brancos - o espiritismo em particular, - penetram nessas religiões, isto é, justamente na medida em que o controle da sociedade perde a sua força, em que a tradição enfraquece” (Bastide, 1973, p. 309).

Em outros momentos, como em Brasil Terra de Contrastes o autor expressa seus receios quanto ao surgimento do preconceito racial em locais em que até então seria inexistente, e suas dúvidas quanto aos efeitos da modernização no litoral nordestino:

“... poderá o novo adaptar-se ao antigo, mostrar-se-á mais propício à pequena indústria artesanal do que é grande indústria capitalista, saberá respeitar as normas arcaicas das relações raciais, da camaradagem afetuosa, do trabalho comunitário? Ou, ao contrário, intensificando a concorrência vital, trazendo a luta de raças para o mercado de trabalho, provocará o aparecimento do preconceito de cor?” (Bastide, 1959, p. 60). 
Em As religiões africanas no Brasil há a visão de um enquistamento cultural presente nos candomblés da Bahia, mas que não se confundiria nem tenderia para o enquistamento racial; e de um enquistamento racial, sem enquistamento cultural no Sul do país. Bastide percebe também a presença de uma integração multirracial na Bahia no quadro do enquistamento cultural. Brancos e mulatos participariam da vida dos candomblés como protetores ou amigos políticos dos terreiros (Bastide, 1971, pp.390-1). Mas em alguns momentos de seu texto surge a constatação da presença de uma estratificação social correspondente a uma estratificação das cores no Brasil, fora do mundo dos candomblés mais tradicionais (Bastide, 1971, p. 435). Quando analisa o espiritismo de umbanda ele percebe a transposição da luta racial do mundo terrestre para o mundo sagrado, o estabelecimento de "barreiras que as leis democráticas impedem que se estabeleçam na sociedade" apareceriam "na sociedade dos espíritos". Neste sentido o sagrado torna-se "local de encontro dos interesses humanos, das atitudes de classe e o reflexo das estruturas urbanas" (Bastide, 1971, pp. 439, 443). Para Bastide a luta racial passa do campo social para o campo místico, sem mudar de caráter. Mas a luta racial assumiria outras formas no Brasil: "trata-se de fazer desaparecer, o mais rapidamente possível, tudo que possa lembrar a África, a fim de diluir as três cores fundamentais do país em uma só cor” (Bastide, 1971, p. 459).

Mas, além disso, o problema das relações raciais dominaria o problema cultural das assimilações:

“...Os fenômenos produzidos entre civilizações diferentes que se encontram, a saber, suas interpretações, suas fusões ou, ao contrário, a vitória de uma sobre a outra, pelo menos no domínio que aqui nos preocupa, o da religião, dependem em última análise de preconceitos, estereótipos, de possíveis discriminações existentes nas (sic) sociedade multirracial, muito mais do que da natureza das civilizações em contato. O sociológico determina o cultural" (Bastide, 1971, p. 514).

Ao citar a resistência religiosa, Bastide não a separa da "resistência racial, negros contra brancos, nem da resistência econômica, escravos contra senhores. A opo- 
sição dos místicos estava comprometida numa luta de cores e num clima de opressão econômica" (Bastide, 1971, p. 525).

Estes são momentos de seus textos que intercalam em graus diferenciados conflitos no universo religioso dos afro-brasileiros. A temática racial apresenta-se através das relações entre brancos e negros e oscila entre uma "democracia racial" onde brancos se ajoelhariam diante das mães-de-santo negras e pobres, onde o "enquistamento cultural" não seria acompanhado de um "enquistamento racial". Também se constata que a interferência e dominância dos brancos neste universo levariam a certos desequilíbrios e à emergência de preconceitos, como no caso citado do espiritismo de umbanda. De certa forma, os conflitos estão sempre latentes, mas num arranjo no qual os afro-brasileiros supostamente detêm certa autonomia, como o do candomblé da Bahia, Bastide enxergaria uma situação racial quase ideal, o que não aconteceria no Sudeste do país, principalmente em São Paulo, palco da modernização, da ascensão social e econômica dos negros brasileiros e também do acirramento de "preconceitos de classe e de cor".

\section{DEMOCRACIA RACIAL E PRECONCEITO DE COR}

As temáticas da democracia racial e do preconceito de classe e de cor aparecem em vários momentos da obra de Bastide. Entretanto as formas de debate encontradas pelo autor nos indicam certas oscilações. A discussão sobre o preconceito de cor ou o preconceito racial na década de 1950 pode ser definida como um traço inovador em sua obra e na de outros autores da época. Mas certos elementos em seu texto nos indicam certo emparelhamento com análises e opiniões correntes contemporâneas, como a do Brasil como uma "democracia racial".

Entendo que Bastide reproduz, em alguns momentos de sua obra, certo senso comum presente em amplos setores da sociedade brasileira, como quando elogia a "democracia racial", e a miscigenação ampla, entre brancos e negros. Esta miscigenação é percebida por ele como processo de "branqueamento" ou de "arianização": 
"toda a demografia está marcada pela mesma política de arianização que domina os aspectos sociais do país, conseqüência de sua democracia racial. As uniões entre gente de cor diferente, quer se processem pelos laços matrimoniais, quer fora deles, quer tomem a forma legal ou a forma costumeira da 'amigação', encaminham-se para o branqueamento progressivo, pois o negro une-se à mulata escura, o mulato escuro à mulata clara, e esta por sua vez ao branco, de modo que os filhos de tais uniões são cada vez mais claros e acabam por se integrar ao grupo dos brancos" (Bastide, 1959, p. 62).

Embora o autor reconheça que a escolha por cônjuges mais claros esteja ligada à consciência dos pais de que filhos mais claros teriam mais facilidade de ascender na escala social, e de que as taxas de mortalidade infantil atingiriam mais as crianças negras (Bastide, 1959, pp. 62-3) - dados que em si demonstrariam a existência de preconceitos profundos na sociedade brasileira Bastide insiste nas imagens da "harmonia racial". A consciência de um desejo brasileiro da arianização da população, e de uma mestiçagem cuja direção é o branqueamento permanecem paradoxalmente em seu texto ao lado de frases como "as relações sexuais entre as cores não são prova de ausência de preconceito racial" (Bastide, 1959, p. 179). Em "A poesia Afro-brasileira” (1943) Bastide inclusive citaria que os "casamentos mistos são os mais frágeis, os mais permeáveis à desorganização" (Bastide, 1973, p. 109).

Em As religiões africanas no Brasil surge outra imagem sobre o negro dentro da democracia racial brasileira:

"É que em verdade o negro, numa democracia racial, é o homem esquartejado. Esquartejado entre a revolta contra o branco que tende a rejeitar, e a revolta contra si mesmo, que aumenta o seu sentimento de inferioridade. Esquartejado entre o protesto africano e a vontade de fundir-se, pela miscigenação, na grande massa branca" (Bastide, 1971, p. 424).

Justaposta a estas análises encontra-se a constatação de que em alguns locais do Brasil, como São Paulo, Rio de Janeiro, Bahia, Pernambuco, Santa Catarina e Rio Grande do Sul, a "população de cor" ainda seria numerosa e 
conservaria em graus diversos elementos herdados das civilizações africanas (Bastide, 1959, p. 63).

Mas São Paulo se apresentaria principalmente como um local onde os negros não teriam válvulas de escape, como no Rio de Janeiro, onde a macumba e o samba exerceriam esta função, de os "livrar de sua condição de raça, civil e politicamente igual, mas social e economicamente inferior". Daí a emergência de movimentos políticos como a Frente Negra. Ele percebe a integração do negro de São Paulo ao "novo sistema econômico de concorrência e de luta pela ascensão social" (Bastide, 1959, p. 136).

Apesar desta exceção, enfatiza-se a imagem do Brasil como o país que conseguiu "unir, num sincretismo tão feliz, civilizações tão diversas como as civilizações indígenas, as civilizações africanas, a civilização portuguesa". Brasil Terra de Contrastes termina com a proposição de que o Brasil teria a vocação para ser um modelo, ou mesmo um mediador entre a África a América e a Europa (Bastide, 1959, p. 250), no que se re-elabora uma das idéias de Gilberto Freyre sobre a vocação internacional do Brasil para a resolução dos problemas de raça (Freyre, s/d, p. 160):

De modo interessante, o exemplo a ser dado para o resto do mundo vem da Bahia, local onde arcaico e moderno se uniriam, no qual a mescla de civilizações demonstraria que uma modernização poderia incluir as diferenças. O exemplo é ao mesmo tempo estranho, pois Bastide achava na época que nos locais de modernização mais acirrada, como São Paulo, as formas religiosas de origem africana foram "deturpadas" ou quase esquecidas pelas populações negras.

Em "A imprensa negra no Estado de São Paulo" (Bastide, 1973[1951]), trabalho no qual o autor pretendia discernir "a mentalidade de uma raça", surgem outras análises sobre a percepção do preconceito. Embora não tendo dados suficientes para caracterizar sociologicamente certos fatos como preconceito de cor ou de raça, ele mostra a importância da percepção do grupo negro:

"Mas o que é fato é que o preto, com ou sem razão, sente que sua ascensão na escala social é perturbada pela existência de 
tal preconceito. Portanto, como representação coletiva do negro, o preconceito inegavelmente existe e é isto que nos importa" (Bastide, 1973, p. 137).

São Paulo, aliás, aparece como um local perigoso para as "relações raciais". George Reid Andrews indica a percepção, por parte de Bastide, de a situação entre brancos e negros em São Paulo poder chegar até a segregação. Isto não ocorreu, mas não deixa de ser sintomático Bastide fazer este tipo de projeção a partir das indicações de que a classe média branca resistiria às possibilidades de ascensão dos negros, criadas pelo aumento dos empregos na indústria e pela expansão da educação pública (Andrews, 1998, p. 260):

"“O branco começou a se sentir ameaçado nos seus postos de direção e de mando. Vai reagir, e essa reação, destinada a manter o negro no fundo da escala social, vai intensificar o preconceito de cor, dar-lhe formas mais agudas, e ao mesmo tempo a segregação vai aparecer em todos os degraus da escala... Uma espécie de solidariedade racial vai estabelecer-se entre as diversas etnias brancas numa mesma política de autodefesa, englobando o brasileiro de 400 anos, o descendente do imigrante e o capitalista estrangeiro" (Bastide \& Fernandes, 1971, pp. 168-169 Apud Andrews, 1998, pp. 260-261).

Em "Manifestações de Preconceito de Cor" (Bastide \& Fernandes, 1955) Bastide indica a dificuldade dos negros em apresentar exemplos de preconceitos de cor no Brasil. Seus relatos indicariam mais preconceitos de classe do que de cor. Esta dificuldade viria das diferenças do Brasil quanto aos países como os Estados Unidos, nos quais se verificaria uma "pressão maciça de um grupo sobre outro". Aqui, os estereótipos

"variam conforme os setores da sociedade; as relações humanas atomizam-se numa poeira de relações inter-individuais; as atitudes raciais variam conforme as famílias ou as pessoas. Entretanto, por trás desse caos aparente, é possível descobrir certas leis" (Bastide \& Fernandes, 1955, p. 123). 
Ele acreditava que o ideal da democracia racial impediria manifestações mais fortes, ocultando a "raça sob a classe" e impedindo conflitos mais abertos. Para descobrir os preconceitos no Brasil seria necessário recorrer "não à análise de comportamentos, mas à da ausência de comportamentos". O preconceito de cor apresentar-se-ia na "ausência de um sistema de reciprocidade nas relações entre brancos e negros" (Bastide \& Fernandes, 1955, pp. 124, 126).

A partir de dados de um inquérito sobre casamentos mistos, indicouse a rejeição de casamentos com negros, numa maioria de respostas $(75 \%)$ que apontava como motivo, a suposta inferioridade racial dos negros, contra $25 \%$ que indicavam a rejeição pela sua condição social inferior. A partir deste e de outros dados Bastide vê a possibilidade de existência de um preconceito de cor independente do preconceito de classe, embora subsistissem situações onde se encontraria o preconceito de cor identificado ao preconceito de classe (Bastide \& Fernandes, 1955, pp. 132-134). Neste ponto ele se afasta de autores como Donald Pierson, cuja análise indicaria a ausência de preconceito de cor no Brasil, ausência esta causada pela não ameaça de negros e mulatos ao status social dos brancos. ${ }^{4}$ Bastide matiza esta posição de Pierson, ao afirmar a sua não validade em São Paulo, onde os negros ascenderiam como grupo social (Bastide \& Fernandes, 1955, p.141).

Ao comparar as "situações raciais" no Brasil e nos Estados Unidos, ele percebe que a chamada "linha de cor" facilitaria a ascensão dos negros, pela necessidade destes de criarem seus próprios bancos de crédito, universidades, escolas e redes de profissionais para atendê-los, para fazer frente à segregação dos brancos. Mas ao mesmo tempo, a proibição de casamentos entre brancos e negros em alguns locais dos Estados Unidos, causaria tensões desconhecidas no Brasil "graças a uma miscigenação intensa":

“...A mistura incessante dos sangues faz desaparecer progressivamente as oposições de cor, fundindo-os numa 'raça mo-

\footnotetext{
${ }^{4}$ Para uma análise da obra de Donald Pierson e suas posições quanto à inexistência de preconceitos de cor no Brasil ver Guimarães (1996).
} 
rena', e tende assim a abolir o problema racial da melhor maneira possível, suprimindo simplesmente as raças. Não nos compete, neste relatório, cujo âmbito não ultrapassa os limites de São Paulo, estudar longamente esse fenômeno geral de miscigenação. Devemos somente ver de que modo ela se opera em São Paulo e as suas relações locais com o desaparecimento - ou o desenvolvimento - do preconceito de cor. Devemos também observar cuidadosamente o advento das ideologias racistas que podem interromper, ou pelo menos refrear, esse movimento de supressão das raças negras, da sua fusão progressiva nas raças brancas. Esse racismo, porém, é um fato recente. E desde 1875 vemos acentuar-se em São Paulo o branqueamento da população”.(Bastide \& Fernandes, 1955, pp. 150-1).

Entretanto o autor retoma outra vez a idéia de que a miscigenação, apesar de poder ter como "resultado remoto o desaparecimento do preconceito de cor", não indicaria a inexistência do preconceito. Suas pesquisas indicariam inclusive a rejeição dos casamentos mistos entre brancos e negros, e a rejeição de filhos de casais não "branqueados" (Bastide \& Fernandes, 1955, pp. 151, 157).

Bastide também percebe nos jornais "A Frente Negra" e a "Voz da Raça” a negação das tradições africanas, e a substituição da imagem do "antigo preto, mais africano que ocidental, mais exótico que nacional" pela "imagem do 'novo negro"'. Nisto ele vê a possibilidade de um racismo "penetrado dos valores e das normas dos brancos". Ele também indica uma hesitação dos negros entre o "enquistamento e a miscigenação":

“...De um lado, defende-se o 'mulatismo', considera-se, contra o descendente de imigrantes, que só o brasileiro que tem um pouco de sangue negro nas veias merece o título de brasileiro, exprime-se satisfação e orgulho pela solução dada pelo país ao problema racial. Por outro lado, manifesta-se receio diante do embranquecimento progressivo da população que elimina, pela mestiçagem, os melhores elementos da raça negra" (Bastide \& Fernandes, 1955, pp. 166-167). 
Haveria também a aceitação de estereótipos dos brancos sobre os negros, e a conseqüente criação de campanhas educativas e moralizadoras destes jornais, as quais pretendiam ensinar ao público como se comportar, a importância da educação e insistiam no abandono da bebida e da vadiagem. Para Bastide, o que aparece aqui é a "imagem do "novo negro" simultânea aos "artigos violentos contra as manifestações do preconceito e contra a má fé dos brancos". Segundo ele, haveria "uma flutuação entre o racismo puro, o orgulho da cor, e um sentimento de inferioridade, que leva à imitação do branco, à adoção dos seus pontos de vista, e à tentativa de apresentar a imagem de um negro branco" (Bastide \& Fernandes, 1955, p. 167).

Num trecho no qual se reproduz o relato de um jornalista crítico à tomada de consciência dos negros brasileiros, através dos movimentos negros e de seus jornais, os quais ele classifica como racistas, vê-se algo sui generis: a afirmação de que o Brasil pretendia ser um país branco, através da "absorção" do negro pelos brancos e uma visão peculiar sobre os efeitos da obra de Freyre: “"o lirismo sociológico de Gilberto Freyre, aliado à perda de toda disciplina, permitiu a confusão que hoje se nota e que levou o negro analfabeto à convicção de que o brasileiro legítimo é ele" (Bastide \& Fernandes, 1955, p. 168).

É interessante pensar neste tipo de visão sobre a obra de Freyre, ainda mais quando se pensa que a presença do negro na obra deste autor tem uma função subsidiária diante do branco português. $O$ brasileiro legítimo de Freyre seria a síntese de indígenas, negros e portugueses, mas através de uma relação na qual os primeiros facilitariam a adaptação do terceiro ao novo país descoberto. ${ }^{5} \mathrm{E}$ a miscigenação seria num sentido branqueador. A reprodução deste relato pode indicar certas funções diferenciadas tomadas pelo texto de Freyre, apesar de seu conservadorismo, entre parcelas da população negra.

\footnotetext{
5 Ver Bastos (1986).
} 


\section{NUM EMARANHADO DE POSIÇÕES}

A última parte do texto mostrou que Bastide poderia identificar a rejeição da mestiçagem com racismo - um racismo negro, mais especificamente, a par de outro racismo branco.

Mas até que ponto Bastide seria acrítico quanto à democracia racial ou quanto ao "branqueamento"? Os rumos tomados pela pesquisa da UNESCO em São Paulo indicam a percepção de conflitos, de preconceitos e de novas atitudes no movimento negro, mas também a preservação de certa subserviência dos negros aos padrões morais e éticos relacionados aos brancos. A África e suas formas culturais, preservadas em certos locais do Brasil, deveriam ser esquecidas, negadas pelo "novo negro". Isto deveria incomodar profundamente Bastide, que estudara centros populacionais como Salvador, onde o candomblé nagô permanecia como aporte cultural e social importante, paralelo à integração dos negros à sociedade brasileira, ao mesmo tempo em que os resignificava através da religião as relações entre brancos e negros.

Para Antonio S. Guimarães seriam visíveis na obra de Bastide dois momentos na percepção das relações raciais no Brasil: um no qual suas impressões seriam influenciadas por Freyre, a partir de 1944, e outro, no qual essas impressões se modificariam, em 1950, com a pesquisa conjunta com Florestan Fernandes sobre as relações entre brancos e negros em São Paulo. O encontro com Freyre em 1944 e o contato com a sua obra, faz Bastide refletir sobre "a ordem social própria à democracia brasileira, ordem que seria baseada na ausência de distinções rígidas entre brancos e negros". Neste contexto Bastide usa a expressão "democracia racial” (Guimarães, 2002, pp.141-3). Para ele, a democracia brasileira seria social e racial:

“... 'Social', entretanto, num sentido muito preciso, que nada
tem a ver com os direitos sociais... Seria, antes, a constituição
de uma ordem social em que a raça teria evoluído para a 'clas-
se', mas na qual o 'povo' daí resultante não teria copiado a
expressão cultural pequeno-burguesa, européia e puritana, tal Temáticas, Campinas, 11(21/22):101-126, jan./dez. 2003 
como nos Estados Unidos, mas construído uma forma original de cultura miscigenada, livre e festiva. A democracia a que Bastide se refere, inspirada em Freyre e Amado, não pode ser reduzida a direitos e liberdades civis, mas alcançaria uma região mais sublime: a liberdade estética e cultural, de criação e convívio miscigenado" (Guimarães, 2002, p. 144).

No estudo conjunto para a UNESCO, de Bastide com Florestan Fernandes, haveria a percepção da "democracia racial" como um ideal. Segundo Guimarães, em Relações Raciais entre Negros e Brancos em São Paulo existiria a conciliação entre a "realidade do 'preconceito de cor'...[e o] ideal da 'democracia racial", tratados como "prática e norma sociais, as quais podem ter existências contraditórias, concomitantes e não necessariamente excludentes". Entretanto o conceito teria mudado de significado em 1955, significando então "um ideal de igualdades de direitos e não apenas de expressão cultural, artística e popular" (Guimarães, 2002, p. 148).

O conceito de "democracia social e étnica" em Freyre não possuiria o sentido de "direitos de representação e autenticidade de minorias étnicas ou raciais". Para Elide Rugai Bastos,

"em Gilberto, esse caráter [ibérico] responsável pela harmonia social, leva a que a democracia política passe a segundo plano, uma vez substituída pela democracia étnica/social. Mais ainda, justifica a não adoção, no Brasil, de medidas sociais e políticas universais, pois as mesmas não caberiam em uma sociedade marcada pela heterogeneidade, caracterizada por uma formação não tipicamente ocidental" (Bastos, 2001, p. 62 Apud Guimarães, 2002, pp.151-2).

Freyre acreditava que a experiência étnica e cultural do encontro das "três raças e três culturas" resultaria numa fusão em "condições que, de modo geral, são socialmente democráticas, ainda que até agora tenham permitido a definição de um tipo ainda imperfeito de democracia social: imperfeito tanto na sua base econômica como nas suas formas políticas de expressão". Entretanto, para Freyre o Brasil impor-se-ia como "comunidade 
cuja experiência social pode servir de exemplo ou estímulo a outras comunidades modernas", pela solução "democrática" e "cristã" dada aos "problemas das relações sociais entre homens de origens étnicas diversas" (Freyre, s/d, p. 132). Para Freyre o "amalgamento de raças e de interpenetração de culturas" seria o exemplo mais alto de um processo "social e etnicamente democrático" (Freyre, s/d, p. 182).

Termino com uma questão: teria Bastide comprado totalmente a versão da "democracia social e étnica" ou da "democracia racial" de Freyre? Os negros deveriam desaparecer totalmente, no processo da "miscigenação das raças"?

Andrews cita como em 1979 Freyre chamou a atenção para a "morenidade" no Brasil, ao tentar combater a restauração da raça como uma categoria informativa do Censo de 1980, exigência esta de ativistas negros e de intelectuais brancos. Mas em

"um sentido mais amplo, estratégico, ele estava enfatizando o conceito de morenidade porque o enxergava como um meio pelo qual o Brasil se transformaria num país 'além da raça', em que as desigualdades e tensões raciais não mais desgastavam e preocupavam o país quanto o haviam feito no passado. Desse modo, promover a categoria racial do moreno (que, como ele indicou... libertaria os brasileiros dos antigos rótulos raciais branco-preto-amarelo) foi parte do trabalho de Freyre de tentar difundir e afastar as poderosas tensões do passado e presente racial do Brasil. Ironicamente, no entanto, o próprio tratamento que Freyre deu à morenidade tende a evocar o antigo sonho de branqueamento" (Andrews, 1998, p. 386).

De muitas formas Bastide pode ter compactuado com este ideal esboçado por Freyre. O país da mestiçagem é visto positivamente por Bastide, mas é traduzido, principalmente, como o país que apresentaria a ausência de preconceitos em alguns locais; mas também como o país onde a "democracia racial" seria vista ao lado de preconceitos inscritos no processo de miscigenação entre brancos e negros, o que também é enfatizado na leitura de Guimarães. 
Bastide apresenta em Relações Raciais entre Negros e Brancos em São Paulo (1955) uma série de imagens e relatos que nos indicam um posicionamento que tem suas raízes nos debates da época. A miscigenação aparece como um dos elementos da democracia racial, e é vista como uma característica positiva diante de exemplos como a segregação racial nos Estados Unidos. Mas reproduz de forma acrítica um senso comum, um elemento da mentalidade do período, quando indica sua direção branqueadora. Bastide reproduz este debate da época, e por vezes chama a miscigenação de "arianização", mas também indica que a miscigenação não indicaria sempre a ausência de preconceitos.

Segundo Guimarães, Bastide utilizaria a categoria de "embranquecimento" para falar do comportamento do negro brasileiro, enfatizando seu caráter aculturado, o qual distanciaria o negro de sua própria cultura:
"evocando uma certa inautenticidade naquilo que esses negros consideravam 'brasileiro' e que ele, Bastide, implicitamente, considerava 'branco'. Do mesmo modo, era considerado 'embranquecimento' a absorção pelos negros de certos pa- drões de comportamento das classes médias e altas, o que significava, também subrepticiamente, que não havia lugar pa- ra negro nessas classes" (Guimarães, 2002, p. 86).

A análise de Guimarães sobre este aspecto levanta questões importantes para pensarmos a época em que Bastide escreve, e seus posicionamentos quanto à questão da cultura afro-brasileira. Bastide tinha uma posição cética quanto aos processos modernizadores, o que pode ser visto inclusive na sua crítica à assimilação (Peixoto, 2000, p. 195; Bastide, 1970). Certa imagem do "negro", constituída pela obra de Bastide, principalmente a relacionada aos estudos sobre religião, não é a do que deve ser assimilado, mas o do que tem algo importante a oferecer à sociedade. Neste sentido a análise de Guimarães perde de vista certas características importantes do pensamento de Bastide, que não pode ser desvinculado de um contexto mais específico, como o das discussões intelectuais da década de 1950. 
Outra preocupação nestes textos é a ascensão do preconceito de cor em São Paulo, tanto por parte de brancos como de negros. A concorrência econômica criaria novas relações, mas acima de tudo um novo negro, o qual renegaria o passado africano e tentaria assimilar certos valores considerados brancos.

A participação de Bastide no projeto da UNESCO é visto por alguns autores como parte secundária de sua produção intelectual e também em comparação com o trabalho de Florestan Fernandes (Maio, 1997, p. 138). Entretanto, Marcos Chor Maio vê a participação de Bastide nesta pesquisa sob outra ótica,

\begin{abstract}
"tanto pela sua visibilidade no contexto internacional no decorrer da pesquisa e na análise de seus resultados..., quanto pelo enfoque distinto sobre as relações entre brancos e negros, quando comparado com a de Florestan Fernandes. Bastide tem uma visão matizada do preconceito racial em São Paulo, revelando que o fenômeno permearia tanto pretos quanto brancos e no contexto das diversas classes sociais" (Maio, 1997, p. 139).
\end{abstract}

Segundo Maio, a sociedade analisada onde se manifestaria o preconceito de cor seria conseqüência da industrialização, da urbanização, da forte presença de imigrantes, e de uma configuração onde as classes sociais conviveriam simultaneamente com a antiga estrutura social, "apresentando... um quadro diferenciado de manifestações contra negros e pardos, que se revelam, seja de maneira mais aberta, seja de modo sutil".

Bastide atribuiria à ideologia da democracia racial certo papel na variedade de comportamentos dos brasileiros diante do preconceito de cor. Ele "interpreta a ideologia tradicional das relações raciais no Brasil, ora como falsa consciência, mistificação, ora como expressão de valores constitutivos de determinada identidade coletiva". O autor também enfatizaria as ambigüidades do processo de miscigenação, o qual encobriria o preconceito de cor por meio dos estereótipos sexuais sobre os negros (Maio, 1997, p. 141, 148). 
Em sua análise de Relações Raciais entre Negros e Brancos em São Paulo Maio indica como Florestan Fernandes via no fenômeno da miscigenação algo contrário à democratização das relações sociais, e assinala sua percepção da ideologia da integração nacional, a qual "encobriria o preconceito racial, dificultando assim a criação de instrumentos racionais adequados à superação das desventuras e dos anseios da massa negra" (Maio, 1997, pp. $132,136,138)$. Numa entrevista na qual Fernandes indicava certas divergências quanto a Bastide, podemos ver a indicação de certas oscilações no pensamento deste, que se verificam em vários momentos de sua obra. Florestan afirma que:

“ 'Ele não tinha uma posição firme com relação a se havia ou não preconceito, se havia ou não democracia racial.

Ele dominava igualmente o campo da antropologia, da sociologia e da psicologia. Com hipóteses psicológicas, por exemplo, ele muitas vezes tendia a pensar que certos comportamentos e alegações eram produtos da auto-defesa do negro, para se proteger das suas próprias deficiências. Outras vezes, ele pensava que os brancos de fato camuflavam a realidade, sem que, com isso, tivessem a intenção de excluir o negro de participação de certas esferas da vida.

Ele interpretava o Brasil da maneira mais civilizada possível. E aceitava os estereótipos, as auto-avaliações correntes. Eu já vinha predisposto a trabalhar contra elas. Para haver um ajustamento entre nós, sugeri a idéia de um continuum, em que a intensidade de discriminação poderia variar de zero até o máximo ' $x$ '. Indivíduos brancos e negros podem se colocar nesse continuum. É o que acontece. Não há padronização. Encontra-se gente mais aberta ao convívio inter-racial, gente mais fechada. Gente que discrimina, gente que não discrimina. Era preciso uma hipótese como esta para nós podermos trabalhar sem conflito"' (Fernandes, 1995, pp. 4-5 Apud Maio, 1997, p. 175).

Esta percepção de Fernandes, juntamente com a sua caracterização do gosto de Bastide pelos "meios-tons" nas análises sobre a situação racial brasileira nos reafirmam a existência de oscilações no pensamento e na obra 
de Bastide. Numa carta a Métraux na qual agradecia o convite para participar do projeto da UNESCO, Bastide mostra mais uma vez estas oscilações, ao afirmar que seria

" 'obligé de démystifier le mythe de la démocracie raciale du Brèsil en montrant qu'elle n'était qu’un autre nom pour désigner un système tout aussi discriminatoire quoique sous une autre forme, le paternalisme" " (Morin, 1994 Apud Maio, 1997, pp. 174-5). ${ }^{6}$

A verificação de fases na obra de Bastide não pode ser tão clara, como indicou Guimarães, ao localizar uma fase de influência de Freyre e outra na qual Bastide estaria engajado no projeto da UNESCO. Anos depois da carta de agradecimento a Métraux e das conclusões da pesquisa publicadas em Relações Raciais entre Negros e Brancos em São Paulo (1955), surge o texto de Brasil Terra de Contrastes, publicado em 1957 na França. Neste livro Bastide apresenta ao seu público francês uma visão que retoma muitas colocações freyreanas, e que à sua maneira faz o elogio da miscigenação e da harmonização de contrastes, embora fale de conflitos neste processo. Para Bastide

“...Existem forças de antagonismo no interior das forças de adaptação, de acomodação, de assimilação, do mesmo modo que as forças de acomodação existem no interior das forças em conflito e no jogo dos contrastes.

Assim, o sociólogo que estuda o Brasil não sabe mais que sistema de conceitos utilizar. Todas as noções que aprendeu nos países europeus ou norte-americanos não valem aqui”. (Bastide, 1959, p. 11).

Para Fernanda Peixoto, os dois capítulos de Roger Bastide em Relações Raciais entre Negros e Brancos em São Paulo (1955) analisariam o preconceito através das atitudes e comportamentos de brancos e negros, a partir de suas posições de grupo e de classe social. Mas, além disso, mostrariam a necessidade de

\footnotetext{
${ }^{6}$ Fernanda Âreas Peixoto (2000, p. 189) afirma que em Florestan Fernandes o "mito da democracia racial - caracterizado como ideologia dificultadora do reconhecimento do racismo e da discriminação entre nós - ... sequer é nomeado nos trabalhos da década de 50 ”.
} 
"observar que a industrialização e a urbanização da cidade de São Paulo não significam o rompimento com o passado...Essa sociedade 'não cristalizada', portanto, que não é puramente capitalista, nem mais senhorial, se caracteriza pelo choque de valores, dos velhos (dos tempos da escravatura) com os novos. Essa situação interfere nos modos de expressão - absolutamente heterogêneos - do preconceito de cor entre a população urbana de São Paulo. Os que negam o preconceito, mostra Bastide, reagem por uma atitude de fidelidade ao ideal da democracia racial; ideal este, continua ele, que impede as manifestações demasiado brutais, disfarça a raça sob a classe, limita os perigos de um conflito aberto'. Disso resulta um preconceito velado... e a formação de barreiras 'ocultas' que segregam e discriminam” (Peixoto, 2000, p. 189).

Estas contradições da realidade brasileira não encontram uma solução no pensamento de Bastide, ao que parece. Talvez isso explique, em parte, a sua necessidade de oscilar entre interpretações, entre referenciais tão díspares. O seu argumento reproduz parte das incongruências da própria sociedade que tenta desvendar, na busca de um meio termo.

Mas talvez seja Florestan Fernandes quem tenha percebido algo essencial na obra de Bastide, ao afirmar que seus textos para o projeto da UNESCO "demonstram que o apego estrito à objetividade científica ia a par com o nuançamento dos elementos chocantes, com uma dialética proudhoniana, que exibia o mal sem ignorar o bem, ou o mau sem desdenhar o bom" (Fernandes, 1986, p. 15 Apud Maio, 1997, p. 139).

\section{OS LIMITES}

Pode-se notar que embora Bastide estivesse localizado num momento de discussões sobre a modernização e o desenvolvimento brasileiro, e se posicionasse criticamente quanto às péssimas condições de saúde e de educação da população brasileira (Bastide, 1959, p.222), ou se envolvesse na interpretação e pesquisa sobre os movimentos negros ou sobre o preconcei- 
to de cor em São Paulo (Bastide \& Fernandes, 1955), ao mesmo tempo ele corrobora posições que excluiriam a discussão teórica de direitos universais ou um debate mais amplo sobre cidadania. Estes temas não se colocam diretamente na maior parte de seus textos. Na maior parte do tempo, é a análise através da "outra extremidade da luneta" (Bastide, 1971,p. 103) que o interessa, o detalhe, a religião da população de origem afro-brasileira, o particularismo. No caso da pesquisa das relações raciais em São Paulo, ela se coloca como percepção de um problema possível, e que muitos pretendiam considerar como inexistente. Neste sentido os trabalhos de Fernandes e de Bastide nesta pesquisa abrem espaço para a discussão da existência ou não da "democracia racial", de uma sociedade que se achava inatamente igualitária.

Pode-se dizer que eles abrem espaço para a discussão da desigualdade racial e social. A imagem do Brasil como "democracia racial" ainda encantava um mundo abalado com os resultados de aplicação da ciência eugênica mais radical pela política nazista e as apreciações sobre a possibilidade de existência do preconceito racial em São Paulo não mereceu a publicação internacional pela UNESCO. E embora Bastide percebesse a possibilidade do preconceito e o denominasse assim na sua correspondência para a UNESCO, ele, em muitos momentos de sua obra não descartou inteiramente a paisagem freyreana das relações raciais harmoniosas.

Não se pode dizer estritamente que esta é uma questão despolitizada. Levantar a temática do preconceito como fizeram alguns autores não deixa de ser uma forma de abordar um problema político e social como a desigualdade. Embora, na maior parte dos autores desse tempo não haja um desenvolvimento da questão em termos de discussões teóricas sobre direito e cidadania - o que até certo ponto pode ser entendido como limitação duma época que presenciou e herdou as conseqüências de uma sucessão de oligarquias, ditaduras, e perseguições políticas ferozes- pode-se entender o esforço de Bastide como uma forma - mesmo que limitada e nem sempre livre de oscilações e contradições - de dar voz e visibilidade nova a certos setores da população brasileira, e de levantar problemas e apresentar análises 
importantes para a época sobre a sociedade. A oscilação interna aos seus textos também pode ser entendida como forma de incorporar, de descrever as oscilações próprias da sociedade brasileira: o texto e as interpretações vêem a realidade racial segundo a constatação da oscilação de pontos de vista.

Cada tempo e cada autor têm suas limitações. Bastide faz parte de um conjunto de autores, que se não desmascaram ou reinterpretam a realidade social brasileira de um certo modo, não deixam de ter seu valor e de representar papéis importantes na construção da sociologia e na elaboração de temas que dialogam com as necessidades de sua época. Eles constroem interpretações com termos e categorias significantes para decodificar a sociedade. A escolha de categorias, temas e teorias, e mesmo o tipo de interpretação que se apresentam nos textos de Bastide são termos que circulam entre conjuntos diferenciados de autores, seja no Brasil ou no exterior. Mas a sua grande necessidade é dar conta da realidade brasileira. Oscilar nesta dialética proudhoniana, como definida por Fernandes, ou mesmo entre o universal e o particular talvez fosse a forma de Bastide descrever e interpretar o Brasil. No país em que se ignorariam quase por inteiro as questões levantadas no resto do mundo sobre o papel do Estado, sobre a cidadania, sobre a igualdade, elaborava-se um outro tipo de discussão. O pensamento reacionário presente em Nina Rodrigues, e na proposição da desigualdade inata entre os negros e brancos, e nas políticas da Constituinte de 1933-34 e depois nas políticas efetuadas pelo governo de Vargas, com referência à imigração, indicam a necessidade de teorizar e de tornar norma a desigualdade entre os seres humanos. Se em Freyre há a corroboração da desigualdade e da exclusão social através da imposição da imagem harmoniosa das relações raciais, não se pode deixar de perceber que em Bastide há uma apropriação e uma inversão de Freyre: as relações são historicamente harmoniosas em alguns locais, mas a desigualdade é denunciada em São Paulo e em outros pólos de modernização. Mas mais do que isto, o particularismo, a religião afrobrasileira se torna local de inversão social, de proposição de outra forma de se colocar diante da sociedade patriarcal e normatizadora. Neste particular se 
encontra a possibilidade de explosão da desigualdade. A harmonia racial não se dá por um favor do branco, como em Freyre, mas através da forma da religião negra e africana, nicho de harmonia entre brancos e negros.

Bastide também pode ser retomado para uma visão crítica da modernidade/modernização como substituta inexorável da tradição, e como uma visão diferenciada sobre a alteridade. ${ }^{7}$ Deve-se perceber o ceticismo de Bastide quanto à modernidade e à modernização, cuja contrapartida é a valorização cultural do "outro" e das possibilidades trazidas por ele. Neste sentido há uma forte escolha pelo particular, em relação ao universal, em muitos momentos de sua obra, mas a oscilação entre estas dimensões também não deixa de ser uma constante.

Agradecimentos: Expresso meus agradecimentos aos Professores Doutores Elide Rugai Bastos, Fernando A. Lourenço, Walquíria L. Rego e a Alexandro D. Trindade, Marcus A. S. Magalhães e Renata Senna Garraffoni.

SUMMARY: Roger Bastide is one of the researchers, which helped to define racial prejudice as a subject in Brazil. However, to study subjects as "color prejudice" and "racial democracy" in Bastide's though it is important to define the intellectual strategies he has chosen or even the internal antagonisms of his texts. In this paper, I shall analyze the race theme on some of Roger Bastide's texts.

KEYwORDS: Roger Bastide; Brazilian social thought; intellectual history; racial relationships; color prejudice; racism; candomble.

${ }^{7}$ Fernanda Peixoto (2000, p. 205) diz que "O primitivo e o arcaico na obra de Bastide ensinam menos sobre o passado e sobre as origens do que sobre o presente que eles problematizam e colocam em cheque. A diferença, portanto, mostra-se extremamente profícua como instrumento de indagação da nossa sociedade, oferecendo inclusive modelos - utópicos - que orientem a sua transformação". 


\section{REFERÊNCIAS BIBLIOGRÁFICAS}

ANDREWS, G. R. Negros e Brancos em São Paulo (1888-1988). Bauru/São Paulo: Edusc, 1998, 444p.

BASTIDE, R. Brasil terra de contrastes. São Paulo: DIFEL, 1959.[1ª . ed. francesa 1957], 256p.

. O Candomblé da Babia (Rito Nagô). 2a ed. São Paulo: Ed. Nacional;

Brasília, INL, 1978.[1ª . ed. francesa 1958], 298p.

. Estudos Afro-brasileiros. São Paulo: Ed. Perspectiva, 1973, 384p.

. Imagens do Nordeste Místico em branco e preto. Rio de Janeiro: O Cruzei-

ro, 1945, 247p.

. Le Prochain et le Lontain. Paris: Cujas, 1970, 303p.

- As Religiões Africanas no Brasil: contribuição a uma sociologia das interpe-

netrações de civilizações. Vol. I e II. São Paulo: Livraria Pioneira Editora/ EDUSP, 1971. [1ª . ed. francesa 1960]

BASTIDE, R. \& FERNANDES, F. Relações Raciais entre Negros e Brancos em

São Paulo. São Paulo: Ed. Anhembi Ltda. , 1955, 554p.

. Brancos e Negros em São Paulo: ensaio sociológico sobre aspectos da formação, manifestações atuais e efeitos do preconceito de cor na sociedade paulistana. São Paulo: Comp. Ed. Nacional, 1971, 310p.

BASTOS, E. R. Entre Dom Quixote e Alonso El Bueno: Gilberto Freyre e o pensamento hispânico. São Paulo: manuscrito, 2001.

. Gilberto Freyre e a Formação da Sociedade Brasileira. São Paulo, Tese de Doutorado - Ciências Sociais/PUCSP, 1986.

FERNANDES, F. Florestan ataca o consenso (entrevista concedida a Jose Luis Silva). In: Folha de São Paulo, Caderno Mais, 1995.

As Relações Raciais em São Paulo Reexaminadas. In: SEMINÁRIO DE CULTURA BRASILEIRA, 4, São Paulo, 1984. Revisitando a Terra de Contrastes: a atualidade da obra de Roger Bastide (org. de Olga R. M. Simson. São Paulo: FFLCH/CERU, 1986, pp. 13-19. 
FREYRE, G. Interpretaşão do Brasil: aspectos da formação social brasileira como processo de amalgamento de raças e culturas. Lisboa: Dois Mundos/Livros do Brasil Ltda., s/d, 210p.

GUIMARÃES, A.S.A. Cor, classe e Status nos estudos de Pierson, Azevedo e Harris na Bahia: 1940-1960. In: MAIO, M. C. e SANTOS, R. V. (org.). Raça, Ciência e Sociedade. Rio de Janeiro: FIOCRUZ/CCBB, 1996, pp. 143-157.

. Classes, Raças e Democracia. São Paulo: FUSP/Editora 34, 2002, 232p.

MAIO, M. C. A História do Projeto UNESCO: estudos raciais e ciências sociais no Brasil. Rio de Janeiro, 1997, 346p. Tese (Doutorado em Ciência Política) - IUPERJ.

MORIN, F. M. Les Inédits et la Correspondance de Roger Bastide. In: P. Laburthe- Tolra (ed.), Roger Bastide ou le Réjonissement de l'Abime. Paris: Éditions L'Harmattan, 1994, pp. 21-42.

PEIXOTO, F. A. Diálogos Brasileiros: uma análise da obra de Roger Bastide. São Paulo: Editora da Universidade de S. Paulo, 2000, 224p.

RAMOS, A. O Negro Brasileiro, etnografia religiosa e psicanálise. Recife: Fundação Joaquim Nabuco/Ed. Massangana, 1988. [2a. Ed. 1940], 303p. 